\title{
Dificuldades na alfabetização: as contribuições da avaliação psicopedagógica para o plano interventivo escolar
}

\author{
Difficulties in literacy: the contributions of psych pedagogical assessment to the school intervention
} plan

\section{Dificultades en la alfabetización: los aportes de la evaluación psicopedagógica al plan de} intervención escolar

\section{Resumo}

A presente pesquisa teve seu apoio no pressuposto de que a avaliação psicopedagógica de um sujeito que apresenta algumas dificuldades no processo de alfabetização pode contribuir na elaboração de uma proposta pedagógica que promova o sucesso de sua aprendizagem. Nesse ínterim, traçou-se como objetivo fazer uso da avaliação psicopedagógica como instrumento de identificação das dificuldades relacionadas à aquisição das habilidades de leitura e escrita, a fim de identificar possíveis caminhos de intervenção pedagógica. De viés qualitativa, com a adoção de procedimentos e levantamentos de questões socioambientais, análise documental, aplicação de protocolos, análise dos dados encontrados e recomendações, a base teórica foi ancorada nos postulados das Ciências Sociais, em observância às ideias de pesquisadores das área de educação (Jardini, 2010; Illich, 2002; Ferreiro e Teberosky, 1985) e dos estudos da neuroaprendizagem (Capellini, Smythe, \& Silva, 2012; Capovilla \& Seabra, 2012a, 2012b, 2013; Seabra, Trevisan, \& Capovilla, 2012; Sánches 2004). Concluiu-se que os resultados obtidos via avaliação psicopedagógica apontam caminhos para a elaboração de atividades de cunho pedagógico que podem contribuir para a aprendizagem da criança.

Palavras-chave: Avaliação psicopedagógica; Alfabetização; Intervenção.

\begin{abstract}
This research was supported by the assumption that the psychopedagogical evaluation of a subject who has some difficulties in the literacy process can contribute to the elaboration of a pedagogical proposal that promotes the success of their learning. In the meantime, the objective was to make use of psychopedagogical assessment as an instrument to identify the difficulties related to the acquisition of reading and writing skills, in order to identify possible ways of pedagogical intervention. From a qualitative point of view, with the adoption of procedures and surveys of socio-environmental issues, document analysis, application of protocols, analysis of the data found and recommendations, the theoretical basis was anchored in the postulates of Social Sciences, in compliance with the ideas of researchers in the field of education (Jardini, 2010; Illich, 2002; Ferreiro e Teberosky, 1985) and neurolearning studies (Capellini, Smythe, \& Silva, 2012; Capovilla \& Seabra, 2012a, 2012b, 2013; Seabra, Trevisan, \& Capovilla, 2012; Sánches 2004). It was concluded that the results obtained through psychopedagogical evaluation point to ways for the elaboration of pedagogical activities that can contribute to the child's learning.
\end{abstract}

Keywords: Psychopedagogical evaluation; Literacy; Intervention.

\section{Resumen}

Esta investigación se sustenta en el supuesto de que la evaluación psicopedagógica de un sujeto que presenta algunas dificultades en el proceso de alfabetización puede contribuir a la elaboración de una propuesta pedagógica que promueva el éxito de su aprendizaje. Mientras tanto, el objetivo fue hacer uso de la evaluación psicopedagógica como instrumento para identificar las dificultades relacionadas con la adquisición de habilidades lectoras y escritas, con el fin de identificar posibles vías de intervención pedagógica. Desde el punto de vista cualitativo, con la adopción de procedimientos y levantamientos de aspectos socioambientales, análisis de documentos, aplicación de protocolos, análisis de los datos encontrados y recomendaciones, la base teórica se ancló en los postulados de las Ciencias Sociales, en cumplimiento de las ideas de los investigadores en el campo de la educación (Jardini, 2010; Illich, 2002; Ferreiro e Teberosky, 1985) y estudios de neuroaprendizaje(Capellini, Smythe, \& Silva, 2012; Capovilla \& Seabra, 2012a, 2012b, 2013; Seabra, Trevisan, \& Capovilla, 2012; Sánches 2004) Se concluyó que los resultados obtenidos a 
través de la evaluación psicopedagógica apuntan a caminos para la elaboración de actividades pedagógicas que pueden contribuir al aprendizaje del niño.

Palabras clave: Evaluación psicopedagógica; Literatura; Intervención.

\section{Introdução}

Na idade medieval, saber decifrar os códigos expressos por letras, com a finalidade de lê-los, era tarefa para poucos. O pedagogo/professor era como um guia que ajudaria o estudante a captar o 'bem' por meio dessa ação. Nos monastérios, alcançar o conhecimento era sinônimo de alcançar a sabedoria identificada com o próprio Cristo (Illich, 2002).

$\mathrm{Na}$ sociedade moderna, processos de leitura e escrita exercem importância ímpar para diversos aspectos da vida social. Basta olhar para o derredor para compreender que a linguagem escrita assumiu protagonismo nas mais diversas áreas de conhecimento. Frequentemente a aprendizagem dessas habilidades ocorre com o ingresso da criança no primeiro ano do ensino fundamental.

Nesse ínterim, Cunha, Martins, Kida e Oliveira (2013, p. 49) asseveram:

O domínio pleno da leitura é um dos principais marcos da vida escolar, e seu ensino recebe todo o destaque dos Parâmetros Curriculares Nacionais (Brasil, 1998), pela compreensão de que o processo inicial do "ensino da leitura" logo se converte em "ler para aprender", devendo tornar o estudante cada vez mais autônomo na construção do conhecimento, a medida que progride nos anos escolares. Assim, o sistema de ensino tem o dever de formar "bons leitores".

Geralmente, a alfabetização marca o início do percurso na vida escolar da criança no ensino fundamental. Sua importância é referendada tanto pela legislação, o que a coloca como centro, quanto pelas propostas pedagógicas nos primeiros anos de escolarização. Infelizmente, um grande número de crianças apresenta dificuldades na consolidação desse processo, um dos motivos que levam profissionais e pesquisadores de diversos campos do conhecimento a investigar a aquisição da língua escrita e desenvolver procedimentos para acautelar e/ou amenizar as dificuldades nesse processo.

Para Soares (1999, p. 47), o termo "alfabetização" está relacionado ao domínio de uma tecnologia denominada escrita alfabética e, também, às habilidades legadas ao processo de ler e de escrever, cujo desencadeamento "envolve conhecimento e destrezas variados, como conhecer o funcionamento do alfabeto, memorizar as convenções letra/som e dominar seu traçado, usando instrumentos como lápis e papel ou outros que os substituam".

Detectadas as dificuldades no processo de alfabetização, é comum perceber que alguns professores utilizam recursos como reforço escolar, atividades diversificadas e tarefas extraclasse, outros encaminham a criança para profissionais da saúde buscando investigar transtornos de aprendizagem. Nós, contudo, partindo da perspectiva apresentada por Sánchez (2004), entendemos, com base em Soares (1999, p. 17), que "não faz sentido falar em dificuldade de aprendizagem e não a relacionar com a avaliação e a melhora, quer dizer, com a intervenção".

Existe uma complexidade singular envolvida no processo de aquisição das habilidades de ler e escrever, uma vez que, tais habilidades remontam um elaborado processamento até que a criança se aproprie da compreensão do sistema de escrita. $\mathrm{O}$ sucesso desse processo envolve também a responsabilidade pedagógica e a compreensão de que tais aprendizagens são direitos do aprendiz (Borges, Gomes e Carvalho, 2020).

A questão que aqui se coloca relaciona-se ao fato de que a avaliação de diferentes aspectos do processamento cognitivo-linguístico de crianças em fase de alfabetização auxilia na identificação de medidas que possam ser interventivas, a fim de desenvolver as habilidades em atraso, mesmo antes de encaminhá-la a profissionais da saúde (Capellini, Smythe, \& Silva, 2012). 
Dito isso, destacamos como objetivo central desse estudo de caso apresentar a avaliação psicopedagógica de uma criança que enfrenta dificuldades com o processo de aprendizagem da leitura e escrita, utilizando instrumentos padronizados validados, intentando por meio dos resultados desta apresentar caminhos para possível intervenção escolar e familiar, que possam contribuir para o sucesso escolar da criança.

Para alcançar o objetivo traçado, utilizou-se como método para a construção da pesquisa o estudo de caso. Nos procedimentos adotados para a construção do estudo consideraram-se o levantamento de questões socioambientais (família e escola), análise documental, estudo bibliográfico sobre o tema, aplicação dos protocolos, análise dos resultados e propostas de intervenção.

\section{Metodologia}

De acordo com os pressupostos de Pereira, Shitsuka, Parreira e Shitsuka $(2018$, p. 65) "estudo de caso é uma descrição e análise de algum caso que apresente alguma particularidade que o torna especial”. A partir das investigações, observações e explorações do pesquisado sobre o caso, torna-se possível realizar análise da realidade de uma perspectiva mais geral e, ao mesmo tempo, aprofundada.

Quanto a abordagem adotada, as bases empíricas alicerçaram-se tanto nos pressupostos qualitativos, quanto quantitativos entendendo que "metodologia qualitativa e quantitativa não se excluem e podem ser complementares, permitindo um melhor entendimento do fenômeno em estudo" Pereira, Shitsuka, Parreira e Shitsuka (2018, p. 62).

Os dados coletados para avaliação psicopedagógica foram coletados do dia 03 de setembro a 05 de outubro de 2018, com um total de dez sessões, incluindo a visita que foi feita à escola, quando foi realizada uma reunião que contou com a presença da professora, da coordenadora e ainda da orientadora educacional.

Nesse item apresentaremos os dados gerais do estudante colaborador do estudo. Por uma questão de ética na pesquisa com crianças, sua identidade será preservada, nos reservamos a chamá-lo pelas letras iniciais do seu nome: V.C.S.M., ou apenas pela inicial do seu prenome: V. Contudo, cabe esclarecer que a família foi informada e autorizou a produção dessa pesquisa.

\subsection{Descrição da demanda}

V.C.S.M. tem 06 anos de idade e cursa o $1^{\circ}$ ano do Ensino Fundamental de 9 anos. É estudante de uma escola particular situada no bairro Asa Norte, Brasília, Distrito Federal, mesmo bairro que reside.

No contato inicial com um dos pais da criança fui informada que V. apresentara dificuldades no processo de alfabetização e que por indicação da escola havia passado por avaliação neurológica, exame fonoaudiológico e aguardava por atendimento. Sabendo disso, esclarecemos ao pai sobre a avaliação psicopedagógica com enfoque na neurociência fazendo o convite para que a criança fosse colaboradora e que os resultados da avaliação seriam objeto dessa pesquisa, bem como que a escola e a família receberiam orientação para a abordagem com a criança, a fim de sanar as dificuldades.

\subsection{Resumo da entrevista com a família}

V.C.S.M. reside com os pais e três irmãos: Fe., Fr. e Vr., que possuem 12, 10 e 08 anos de idade, respectivamente. Os quatro filhos do casal são naturais de Caruaru, Pernambuco - cidade em que se efetivou o processo de adoção. O processo adotivo seguiu o regramento e as instâncias estabelecidas pela legislação brasileira, o contato foi feito pela instituição de Caruaru sobre a adoção, após o contato do casal com as três crianças mais velhas, pois ainda não sabiam da existência do mais novo. Todas as crianças têm a mesma família como genitora. V. foi abrigado aos 04 meses de vida, permanecendo até os dois 
anos, quando foi adotado em maio de 2014, alguns meses após a adoção dos seus irmãos, demora que se deu devido a burocracia do processo, uma vez que a criança estava abrigada em instituição diferente dos demais irmãos.

A responsabilidade no acompanhamento dos filhos é dividida entre o casal, o que inclui as rotinas familiares e as atividades das crianças (escola, esporte, tarefas e outras). V. dorme cerca de $9 \mathrm{~h}$ por noite (sem intercorrências), estuda no período matutino e almoça em família. No contra-turno a criança faz ginástica acrobática três vezes por semana. V. tem uma relação mais próxima com o irmão de idade próxima, Vr., e brincam juntos quando não está em alguma atividade dirigida.

Os pais relatam que V. tem um humor muito próprio e parecido com o do irmão mais velho. Geralmente, ele precisa de um posicionamento firme para que execute as tarefas que lhe são dadas, quando isso não acontece costuma manipular a situação. Na escola existe uma queixa de que V., muitas vezes, busca se esquivar da execução da tarefa. Teve dificuldade no traçado da letra cursiva, mas, paulatinamente foi se adaptando. No momento ainda não lê e não escreve com autonomia. Durante as atividades acompanhadas pelos pais apresenta trocas de letras (viso-espacial, surdas/sonoras) e, dificuldades concernentes à memória.

Sobre a vida da criança até o momento de entrada no abrigo relatam que os pais biológicos viviam em situação de rua e faziam uso excessivo de álcool. As crianças viviam em situação de vulnerabilidade física, social e psicoemocional. Sobre os primeiros marcos de desenvolvimento anteriores aos dois primeiros anos e seis meses os pais não puderam responder, pois a criança ainda não estava sob sua guarda. A retirada da fralda se deu de maneira natural, observando os irmãos e com alguns treinamentos. Nessa chegada a criança já estava deixando de usar também a mamadeira e a chupeta, de acordo com os pais, a observação dos irmãos deixou a criança bem autônoma. Quando chegou já estava andando com autonomia e os pais não perceberam intercorrências. Apesar de ser uma criança que frequenta ginástica acrobática e está, de acordo com a técnica, em desenvolvimento ascendente, não anda de bicicleta sozinho, pois, os pais ainda não tiraram as rodinhas. Não se interessa por jogos de tabuleiros e outros que precisam de tempo de atenção tais como quebra-cabeça, jogo da memória e livros. É uma criança cativante que está adaptada à escola e à professora. O pai diz que a criança esquiva-se das atividades escolares, e que esquece o livro para não fazer as tarefas. Não apresenta capricho na organização, mas, por outro lado, possui um bom vocabulário.

Sobre a saúde, apesar de não serem relatadas intercorrências, os pais disseram que a criança fez cirurgia para retirada de amígdala e adenoide e após isso não passou pela fonoaudióloga. Informou também que ele ronca muito durante o sono. Fez exame do Processamento Auditivo Central (PAC) e devido às alterações no resultado a otorrinolaringologista encaminhou a criança ao fonoaudiólogo que iniciara investigação ainda em outubro.

Os pais dizem que a criança gosta de assistir vídeos no YouTube, jogar bola, pebolim, contudo, muitas vezes a rotina exaustiva de trabalho e compromissos dificultam os tempos de brincadeira dos pais com as crianças, mas, sempre que possível, frequentam clube e fazem passeios em família.

\subsection{Dados coletados no questionário investigativo aplicado junto à professora}

De acordo com os dados do questionário investigativo enviado à escola, V. apresenta preferência pelas aulas de educação física. Gosta de jogar futebol, correr e fazer ginástica. Demonstra facilidade em reconhecer seu esquema corporal, bem como realiza com destreza movimentos que envolvem a coordenação motora global e final. Além disso, mantém um bom relacionamento com a docente, mostrando-se prestativo.

O que mais preocupa a docente são as dificuldades com a atenção, concentração e motivação demonstradas pela criança. Os relatos apontam que V. se dispersa durante a realização das tarefas, deixando de concluir grande parte destas. Também não apresentou progressos com relação ao processo de alfabetização, uma vez que, de acordo com a docente, não reconhece o alfabeto e as sílabas o que dificulta que realize a junção silábica com autonomia, e mais, apresenta dificuldades 
relacionadas às sequências numéricas e tarefas que envolvam raciocínio lógico matemático. Diante das dificuldades detectadas a professora regente relata que tem acompanhado individualmente as atividades da criança, retomado atividades com o alfabeto, revisando os conteúdos semanais e disponibilizado assento próximo a ela.

Os pais sempre participam das reuniões marcadas pela escola, demonstram interesse pela vida escolar do aprendente, mostrando-se presentes, participativos e organizados.

\section{Resultados da Avaliação Psicopedagógica}

A partir das informações e queixas colhidas com os pais e a escola e após uma sessão de acolhimento e formação de vínculo com V., foram selecionadas as provas compatíveis com a idade da criança e as queixas apresentadas, para iniciarmos a investigação com a aplicação de testes padronizados, os quais serão descritos nos subitens a seguir com a apresentação do objetivo do instrumento e dos valores obtidos pela criança, observando a Tabela concernente.

\subsection{Teste Atenção por cancelamento}

Permite avaliar o processamento de informações, pensamento ou ações relevantes de uma determinada tarefa, ignorando estímulos distratares ou irrelevantes (Montiel \& Seabra, 2012a).

Tabela 1. Teste de Atenção por Cancelamento.

\begin{tabular}{cccc}
\hline Habilidade & $\begin{array}{c}\text { Resultado Obtido -Escore } \\
\text { bruto }\end{array}$ & $\begin{array}{c}\text { Resultado Esperado para a } \\
\text { Idade }\end{array}$ & Classificação \\
\hline Atenção seletiva & 29 & 20 a 43 & Média \\
Atenção Sustentada & 2 & 0 a 2 & Média \\
AtençãoAlternada & 10 & 11 a 20 & Baixa \\
Total geral & $\mathbf{4 1}$ & $\mathbf{3 4}$ a 56 & Média \\
\hline
\end{tabular}

Fonte: Autores.

\subsection{Teste de trilhas}

Possibilita avaliar a flexibilidade cognitiva, percepção e atenção visual, velocidade e rastreamento viso motor, atenção sustentada e velocidade do processamento. É dividido em duas partes: a primeira avalia a busca visual e serve de base para interpretação da segunda parte, que mede atenção, velocidade e, principalmente, flexibilidade (Montiel \& Seabra, 2012b).

Tabela 2. Teste de Trilhas.

\begin{tabular}{cccc}
\hline Teste & $\begin{array}{c}\text { Resultado Obtido -Escore } \\
\text { bruto }\end{array}$ & $\begin{array}{c}\text { Resultado Esperado para a } \\
\text { Idade }\end{array}$ & Classificação \\
\hline Parte A Sequência & $2-84$ & 2 a 5 & Baixa \\
Parte A Conexões & $1-66$ & 3 a 4 & Muito Baixa \\
Parte B Sequências & $2-89$ & 2 a 7 & Média \\
Parte B Conexões & $1-67$ & 4 a 8 & Muito Baixa \\
\hline
\end{tabular}

Fonte: Autores.

\subsection{Teste de repetição de palavras e pseudopalavras}

Oportuniza avaliar a memória de curto prazo fonológica por meio de uma tarefa de repetição de palavras e pseudopalavras (Seabra, 2012). 
Tabela 3. Teste de Repetição de Palavras e Pseudopalavras.

\begin{tabular}{cccc}
\hline Habilidade & $\begin{array}{c}\text { Resultado Obtido - Escore } \\
\text { bruto }\end{array}$ & $\begin{array}{c}\text { Resultado Esperado para a } \\
\text { Idade }\end{array}$ & Classificação \\
\hline $\begin{array}{c}\text { Memória de curto prazo } \\
\text { repetição de palavras } \\
\begin{array}{c}\text { Memória de curto prazo } \\
\text { repetição de pseudopalavras } \\
\text { Total geral }\end{array}\end{array}$ & 3 & 3 a 5 & Média \\
\hline
\end{tabular}

Fonte: Autores.

\subsection{Prova de consciência fonológica por produção oral}

Possibilita avaliar habilidades de manipular os sons da fala (Capovilla \& Seabra, 2012b).

Tabela 4. Prova de Consciência Fonológica por Produção Oral.

\begin{tabular}{cccc}
\hline Habilidade & $\begin{array}{c}\text { Resultado Obtido - Escore } \\
\text { bruto }\end{array}$ & $\begin{array}{c}\text { Resultado Esperado para a } \\
\text { Idade }\end{array}$ & Classificação \\
\hline Síntese silábica & 4 & 4 & Média \\
Síntese fonêmica & 0 & 1 a 3 & Sem escore \\
Rima & 0 & 2 a 3 & Sem escore \\
Aliteração & 0 & 2 a 3 & Sem escore \\
Segmentação silábica & 4 & 4 & Média \\
Segmentação fonêmica & 0 & 1 a 2 & Sem escore \\
Manipulação silábica & 1 & 2 a 3 & Média \\
Manipulação fonêmica & 0 & 1 a 2 & Sem escore \\
Transposição silábica & 1 & 1 a 3 & Média \\
Transposição fonêmica & 0 & 1 a 2 & Sem escore \\
Total geral & $\mathbf{1 0}$ & $\mathbf{1 1}$ a 26 & Baixa \\
\hline
\end{tabular}

Fonte: Autores.

\subsection{Prova de consciência fonológica por escolha de figura}

Possibilita avaliar habilidades de manipular os sons da fala (Capovilla \& Seabra, 2012a). 
Tabela 5. Prova de Consciência Fonológica por Escolha de Figura.

\begin{tabular}{cccc}
\hline Habilidade & $\begin{array}{c}\text { Resultado Obtido - Escore } \\
\text { bruto }\end{array}$ & $\begin{array}{c}\text { Resultado Esperado para a } \\
\text { Idade }\end{array}$ & Classificação \\
\hline Rima & 3 & - & - \\
Aliteração & 5 & - & - \\
Adição silábica & 3 & - & - \\
Subtração silábica & 3 & - & - \\
Adição fonêmica & 1 & - & - \\
Subtração fonêmica & 1 & - & - \\
Transposição silábica & 1 & - & - \\
Transposição fonêmica & 0 & - & Muito Baixa \\
Trocadilho & 0 & $\mathbf{1 7}$ & $\mathbf{3 2}$ \\
Total geral & &
\end{tabular}

Fonte: Autores.

\subsection{Teste infantil de nomeação}

Possibilita rastrear as alterações relacionadas às habilidades orais. Alguns estudos têm sugerido que a habilidade de nomeação rápida está relacionada e pode contribuir com as habilidades de leitura e escrita, independentemente da habilidade de consciência fonêmica (Seabra, Trevisan, \& Capovilla, 2012).

Tabela 6. Teste Infantil de Nomeação.

\begin{tabular}{cccc}
\hline Habilidade & $\begin{array}{c}\text { Resultado Obtido }- \text { Escore } \\
\text { bruto }\end{array}$ & $\begin{array}{c}\text { Resultado Esperado para a } \\
\text { Idade }\end{array}$ & Classificação \\
\hline Nomeação rápida & 19 & 19 a 36 & Média \\
\hline
\end{tabular}

Fonte: Autores.

\subsection{Teste de discriminação fonológica}

Oportuniza avaliar a habilidade de discriminar fonemas (Seabra \& Capovilla, 2012).

Tabela 7. Teste de Discriminação Fonológica.

\begin{tabular}{cccc}
\hline Habilidade & $\begin{array}{c}\text { Resultado Obtido }- \\
\text { Escore bruto }\end{array}$ & $\begin{array}{c}\text { Resultado Esperado para a } \\
\text { Idade }\end{array}$ & Classificação \\
\hline Discriminação de fonema & 23 & 22 a 23 & Média \\
\hline
\end{tabular}

Fonte: Autores.

\subsection{Teste contrastivo de compreensão auditiva e de leitura}

É dividido em dois subtestes (compreensão de sentenças escritas e faladas), porém, só foi aplicado o subteste de Compreensão de Sentenças Faladas, uma vez que a criança ainda não lê convencionalmente (Capovilla \& Seabra, 2013). 
Tabela 8. Teste Contrastivo de Compreensão Auditiva e de Leitura.

\begin{tabular}{cccc}
\hline Habilidade & $\begin{array}{c}\text { Resultado Obtido }- \\
\text { Escore bruto }\end{array}$ & $\begin{array}{c}\text { Resultado Esperado } \\
\text { para a Idade }\end{array}$ & Classificação \\
\hline $\begin{array}{c}\text { Compreensão de sentenças } \\
\text { faladas }\end{array}$ & 29 & 30 a 37 & Baixa \\
\hline
\end{tabular}

Fonte: Autores.

\subsection{Prova aritmética}

Avalia distintos aspectos abrangentes da competência aritmética (Montiel \& Seabra, 2013).

Tabela 9. Prova Aritmética.

\begin{tabular}{cccc}
\hline Habilidade & $\begin{array}{c}\text { Resultado Obtido - Escore } \\
\text { bruto }\end{array}$ & $\begin{array}{c}\text { Resultado Esperado para a } \\
\text { Idade }\end{array}$ & Classificação \\
\hline Processamento numérico & 4 & 4 a 9 & Média \\
Cálculo & 1 & 2 a 7 & Baixa \\
Total geral & $\mathbf{5}$ & $\mathbf{6}$ a 18 & Baixa \\
\hline
\end{tabular}

Fonte: Autores.

\subsection{0 psicogênese da língua escrita}

De acordo com Ferreiro e Teberosk (1985), a psicogênese da língua escrita possibilita a identificação das hipóteses construídas pelas crianças ao longo do processo de aquisição da escrita. Essas hipóteses compõem uma série de modos de representação que vão sendo construída até que alcance o nível da representação alfabética da linguagem. Contudo, entendemos, como aponta Moreira (2009), que os estudo da linguística relacionados à área de aquisição da escrita nos ajudam a compreender lacunas existentes na teoria psicogenética. Com isso, assumimos aqui que faremos uma análise dos erros a partir da análise do processamento fonológico.

Tabela 10. Teste da Psicogênese.

\begin{tabular}{cccc}
\hline Palavra Ditada & Escrita da Criança & Frase Ditada & Frase Escrita \\
\hline marretada & Maea & O carro levou uma & Uqaoeuuaeda \\
conjunto & Noq & marretada. & \\
carro & Qao & \\
eu & Io & \\
\hline
\end{tabular}

Fonte: Autores.

\subsection{Protocolo para desenvolvimento motor}

Como Instrumento de coleta de dados optou-se pela Escala de Desenvolvimento Motor (EDM) (Rosa, 2002), instrumento que possibilita avaliar o desempenho motor das crianças. De acordo com o autor, o estudo dos elementos básicos da motricidade humana expresso na EDM podem ter caráter multidisciplinar nos campos de conhecimento de educação e saúde (Medicina, Psicologia, Educação Física, Fonoaudióloga, Pedagogia, Fisioterapia, entre outros). 
Tabela 11. Avaliação Motora.

\begin{tabular}{cccc}
\hline Habilidade Avaliada & Idade Motora em Meses & $\begin{array}{c}\text { Idade Cronológica em } \\
\text { Meses }\end{array}$ & Observação \\
\hline Motricidade global & 96 & 78 & A criança apresentou \\
Motricidade fina & 72 & 78 & desempenho acima do \\
Equilíbrio & 96 & 78 & esperado nos testes de \\
Esquema corporal & 60 & & motricidade global e \\
Organização espacial & 60 & 78 & equilíbrio. Vale destacar que \\
Organização temporal/ & 60 & 78 & V. é membro de uma equipe \\
linguagem & 74 & -4 & de ginástica artística. \\
Desenvolvimento motor & & & \\
geral & & &
\end{tabular}

Fonte: Autores.

\subsection{Protocolo da avaliação ecológica - Questionário de capacidade e dificuldades: emoção, hiperatividade,} relacionamento, conduta e pró-social

De acordo com Saur e Loureiro (2012), o Strengths and Difficultie Questionarie (SDQ) ou Questionário de Capacidades e Dificuldades proposto por Robert Goodman em 1997, é um instrumento hábil de rastreamento (screening) de saúde mental proposto para avaliar crianças de 04 aos 16 anos.

Tabela 12. Questionário de Capacidades e Dificuldades - Resposta da família.

\begin{tabular}{cccc}
\hline Habilidade Avaliada & Resultado & $\begin{array}{c}\text { Resultado Esperado para } \\
\text { a Idade }\end{array}$ & Classificação \\
\hline Sintomas emocionais & 1 & 0 a 3 & Normal \\
Problemas de conduta & 0 & 0 a 2 & Normal \\
Hiperatividade & 6 & 0 a 5 & Anormal \\
Problemas com & 0 & 0 a 2 & Normal \\
colegas & 10 & 6 a 10 & Anormal \\
Comportamento pró- & & & $\mathbf{0 ~ a ~} \mathbf{1 3}$ \\
social & $\mathbf{1 7}$ &
\end{tabular}

Fonte: Autores.

Tabela 13. Questionário de Capacidades e Dificuldades - Resposta da escola.

\begin{tabular}{cccc}
\hline Habilidade Avaliada & Resultado & $\begin{array}{c}\text { Resultado Esperado para a } \\
\text { Idade }\end{array}$ & Classificação \\
\hline Sintomas emocionais & 2 & 0 a 4 & Normal \\
Problemas de conduta & 6 & 0 a 2 & Anormal \\
Hiperatividade & 10 & 0 a 5 & Anormal \\
Problemas com colegas & 2 & 0 a 3 & Normal \\
Comportamento pró- & 7 & 6 a 10 & Normal \\
social & 28 & 12 a 15 & Anormal \\
Total & & & \\
\hline
\end{tabular}

Fonte: Autores. 


\section{Análise e Discussão dos Dados da Avaliação}

O Gráfico 1, a seguir, apresenta de maneira copilada as habilidades que foram avaliadas e que os resultados estavam abaixo do esperado para a idade da criança.

Gráfico 1. Habilidades avaliadas aquém do esperado para a idade.

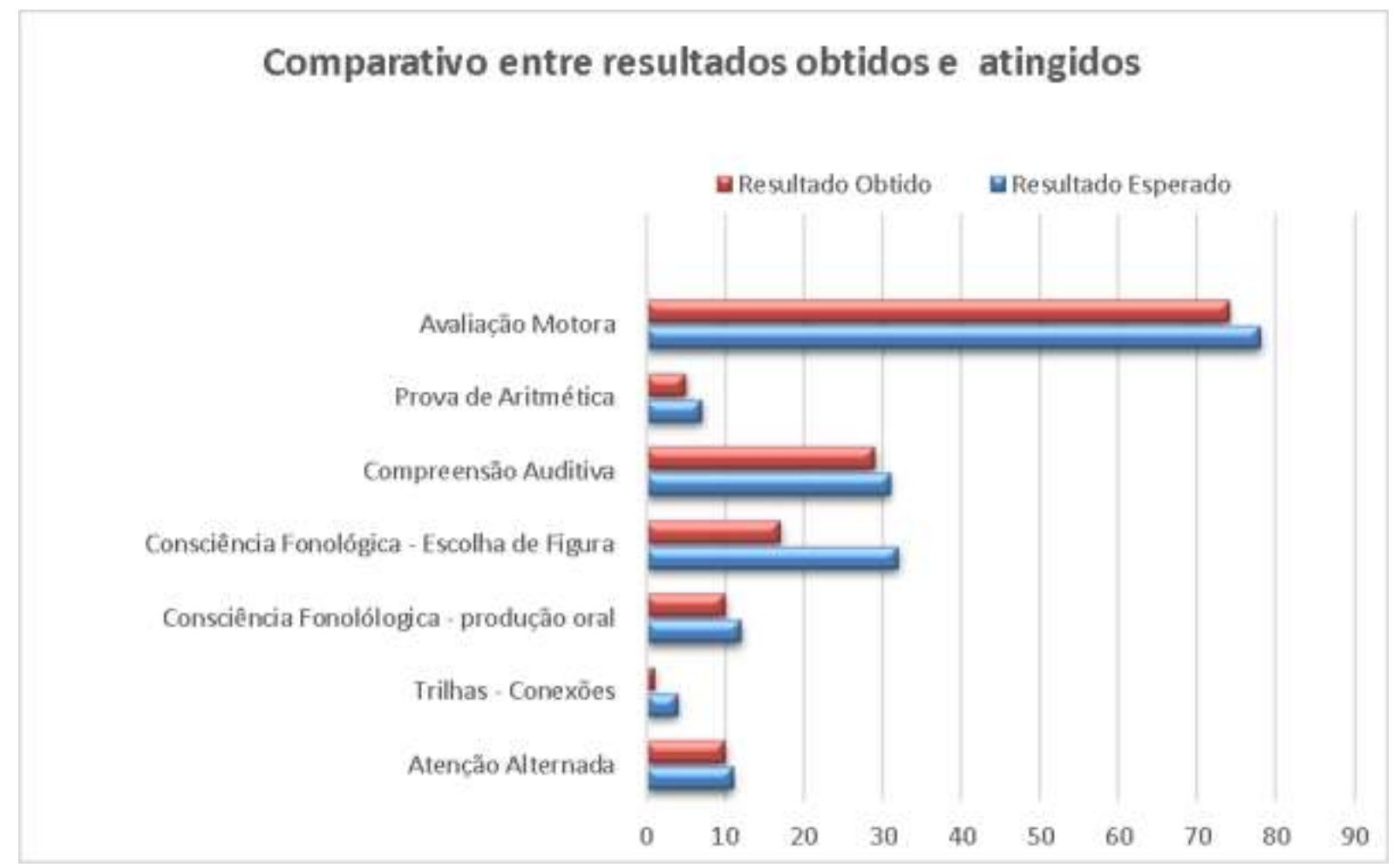

Fonte: Autores.

O Gráfico outrora apresentado traz um panorama das habilidades que estão envolvidas direta ou indiretamente no processo de alfabetização, as quais nosso colaborador apresenta alterações quanto ao resultado esperado para sua idade.

Sobre a avaliação motora, observamos que os itens que se encontram com disparidade ao esperado relacionam-se ao esquema corporal, organização espacial e organização temporal. Sobre essa questão, Rosa et al. (2007, p. 48) destacam que em crianças que apresentam dificuldades de aprendizagem é comum existirem déficits nessas áreas motoras e que se encontram correlações significativas entre o desenvolvimento motor e o baixo rendimento escolar, sendo "que estudos apontam que o perfil motor de crianças disléxicas, de 6 a 10 anos, regularmente atinge a classificação normal baixo".

Com relação à área de aritmética, Menon, citado por Seabra, Dias e Capovilla (2013), ressalta que a resolução de cálculos exige, além da memória de trabalho, que está consistentemente relacionada ao desempenho em matemática de adultos e crianças, processos cognitivos relacionados à manipulação e transformação de informações (funções executivas).

De acordo com Trevisan, Dias e Seabra (2012, p. 19), existem evidências de que alterações em "algumas habilidades de linguagem oral, como consciência fonológica, consciência sintática, vocabulário, memória fonológica e nomeação, podem ser indicadores de distúrbio". Dito isso, vimos que também é importante investigar os aspectos linguísticos gerais para compreender o epicentro das dificuldades de aprendizagem relacionadas à alfabetização.

Silva (2013) acrescenta que problemas relacionados com a aquisição das habilidades de leitura e escrita podem ocorrer transitoriamente, sendo nesses casos classificados como dificuldades de aprendizagem. Contudo, quando se torna permanente, pode ser um indicio de transtorno de aprendizagem. 
A autora ainda acrescenta que dificuldades relacionadas à orientação temporal, espacial, esquema corporal, memória operacional e consciência fonológica podem estar relacionadas à dislexia, uma vez que, de forma geral, os disléxicos apresentam "dificuldade de processar estímulos linguísticos e não linguísticos, breves, rápidos e sucessivos" (Silva, 2013, p. $34)$.

Corroborando as ideias de Jardini (2010), Silva (2013), Capellini, Smythe e Silva (2012) e tantos outros autores que discutem o tema, a identificação precoce de crianças em risco para problemas na aquisição de leitura e escrita minimizam avaliações tardias e equivocadas, mas identificar risco não pode ser confundido com dar diagnóstico.

Ainda com relação a identificação precoce de risco de aprendizagem, cabe esclarecer que, de acordo com os pressupostos de Moro e Carlesso (2019, p. 6) "as crianças não aprendem facilmente por si mesmas, aprendem refletindo, pois, algumas pessoas as colocam em situação de refletir" cabendo ao educador identificar dificuldades da criança e oportunizar aprendizagens por meio de novas propostas e técnicas de ensino, alinhadas à realidade e contexto do aprendiz, com apoio da família.

\section{Considerações Finais}

A compreensão das dificuldades apresentadas pela criança é um elemento indispensável tanto para profissionais que atuam junto a ela, quanto para a família. O entendimento de que as dificuldades são passiveis de serem superadas se forem feitas abordagens eficazes é o primeiro passo para elaboração de um plano interventivo de sucesso. Sobre essa questão, Dias e Oliveira, citado por Seabra et al. (2013, p. 18) destacam que "os problemas de leitura e escrita precisam ser apropriadamente identificados para que se possa determinar qual componente ou componentes específicos estão comprometidos e possa ser oferecido o tratamento mais adequado".

Os testes de consciência fonológica revelam que a criança apresenta dificuldade em processar estímulos linguísticos e não linguísticos sendo assim, o que também fica explícito na avaliação da escrita (psicogênese) é que ela ainda está em processo de compreensão dos princípios da língua, dentre esses, o princípio alfabético que se fundamenta na compreensão de que a língua escrita está relacionada ao processo de consciência, de que as letras representam os sons da fala. V. oscila, ora entende que uma letra basta para representar cada sílaba, com ou sem relação sonora, por ainda não conhecer todas as letras. Algumas vezes escreve sílabas completas e outras vezes volta à hipótese silábica.

A avaliação motora da criança apontou dificuldades nos aspectos de organização temporal e espacial. Dentro do processo da alfabetização estas habilidades também são requeridas, uma vez que não basta identificar os sons das letras (consciência fonológica), mas também é preciso compreender a ordem dentro das palavras (consciência fonêmica). É pela compreensão da ordem dos sons dentro das palavras que se faz o processo de decodificação (Jardini, 2010).

Nesse sentido, destacamos que o foco principal a ser trabalhado como forma interventiva precoce seja direcionado para a questão fonológica. Jardini (2010), Capovilla e Seabra (2012a, 2012b) e Silva (2013) destacam que a intervenção com atividades de consciência fonológica, fonêmica, fonoarticulatórias, percepção e processamento auditivo, manipulação de segmentos da fala, atividades visuo-motoras e habilidades espaço-temporais, bem como o ensino explícito e direto da correspondência grafema/fonema são atuações que colaboram de maneira significativa para a superação das dificuldades encontradas no processo de alfabetização.

Contudo, o que temos acompanhado nos últimos anos é o avanço das atividades escritas e de treinos na educação infantil, o que suprime o tempo que deveria ser destinado a atividades que auxiliam no desenvolvimento integral das crianças e consequentemente contribuem para o processo de alfabetização futuro. Uma vez que este, de acordo com a legislação educacional do nosso país, deveria acontecer entre 6 e 8 anos. A antecipação dessas atividades, como dissemos, muitas vezes não considera a real necessidade de aprendizagem da criança. E o processo de alfabetização torna-se penoso. 
Cabe salientar que as intervenções nas dificuldades do processo de aprendizagem da leitura e escrita para que sejam efetivas precisam partir da compreensão de quais fatores estão envolvidos nesse processo, bem como, localizar os aspectos em que a criança apresenta maiores dificuldades e elaborar um plano interventivo para que estes sejam sanados. Isso, no entanto, não quer dizer que não se deva encaminhar a crianças para avaliação de outros profissionais, apenas reforça a responsabilidade da escola no que diz respeito a identificar e intervir nos casos de dificuldade.

No caso específico do nosso colaborador, observa-se que ampliar o conhecimento das dificuldades apresentadas por ele a partir do estudo e análise detalhada de cada uma são indispensáveis para propor uma prática eficiente do processo de alfabetização, corroborando assim, o que aponta Borges, Gomes e Carvalho (2020, p. 2) sobre fundamentar o material didático a fim de torná-lo mais significativo e compatível às necessidades do aprendiz.

Diante de todas as questões já colocadas aqui, deixa-se como propostas para futuras investigações o levantamento de sugestões para adequações pedagógicas relacionadas aos itens em discrepância apontados pela avaliação psicopedagógica, bem como, uma discussão mais aprofundada dos conceitos de dificuldade e transtorno de aprendizagem.

\section{Referências}

Borges, S. P., Gomes, A., \& Carvalho, E. T. de. (2020). Reflecting on literacy methods in the construction of knowledge. Research, Society and Development, 9(7), e75973787. https://doi.org/10.33448/rsd-v9i7.3787

Capellini, S. M., Smythe, I., \& Silva, C. (2012). Protocolo de avaliação de habilidades cognitivo-linguísticas: Livro do profissional e do professor. Marília, SP: FUNDEPE.

Capovilla, F. C., \& Seabra, A. G. (2012a). Prova de Consciência Fonológica por Escolha de Figura. In A. G. Seabra, \& N. M. Dias (Orgs.), Avaliação neuropsicológica cognitiva: Linguagem oral. 2, 129-131. Memnon.

Capovilla, F. C., \& Seabra, A. G. (2012b). Prova de Consciência Fonológica por Produção Oral. In A. G. Seabra, \& N. M. Dias (Orgs.), Avaliação neuropsicológica cognitiva: Linguagem oral. 2, 117-122. Memnon.

Capovilla, F. C., \& Seabra, A. G. (2013). Teste Contrastivo de Compreensão Auditiva e de Leitura. In A. G. Seabra, N. M. Dias, \& F. C. Capovilla, F. C. (Orgs.), Avaliação neuropsicológica cognitiva: Leitura, escrita e aritmética. 3, 121-128. Memnon.

Cunha, V. L. O., Martins, M. A., Kida, A. S. B., \& Oliveira, A. M. (2013). Estratégias para o trabalho com fluência leitora. In F. H. Pinheiro, G. D. German, \& S. A. Capelli (Orgs.), Manual de estratégia para dificuldades de aprendizagem. Marília, SP: FUNDEPE.

Ferreiro, E., \& Teberosky, A. (1985). A psicogênese da língua escrita (4a. ed.). Artes Médicas.

Illich, I. (2002). En el viñedo del texto: Etología de la lectura: Un comentario al "Didascalicon” de Hugo de San Victor. México: Fondo de Cultura Económica.

Jardini, R. S. R. (2010). Alfabetização e reabilitação pelo método das boquinhas: Fundamentação teórica.

Montiel, J. M., \& Seabra, A. G. (2012a). Teste de Atenção por Cancelamento. In A. G. Seabra, \& N. M. Dias (Orgs.), Avaliação neuropsicológica cognitiva: Atenção e funções executivas. 1, 42-78. Memnon.

Montiel, J. M., \& Seabra, A. G. (2012b). Teste de Trilhas: partes A e B. In A. G. Seabra, \& N. M. Dias (Orgs.), Avaliação neuropsicológica cognitiva: Atenção e funções executivas. 1, 85-92. Memnon.

Montiel, J. M., \& Seabra, A. G. (2013). Prova Aritmética. In A. G. Seabra, N. M. Dias, \& F. C. Capovilla, F. C. (Orgs.), Avaliação neuropsicológica cognitiva: Leitura, escrita e aritmética. 3, 85-96. Memnon.

Moreira, C. M. (2009). Os estágios de aprendizagem da escritura pela criança: uma nova leitura para um antigo tema. Linguagem em (Dis)curso, 9(2), 359385 .

Moro, L. G. B., \& Carlesso, J. P. P. (2019). Difficulties and Distributions of Learning: in The first Years Of Schooling. Research, Society and Development, 8(5), e4385966. https://doi.org/10.33448/rsd-v8i5.966

Pereira, A. S.; Shitsuka, D. M.; Parreira, F. J. \& Shitsuka, R. (2018). Metodologia da pesquisa científica. Editora UAB/NTE/UFSM. Santa Maria-RS

Rosa, F. Neto. (2002). Manual da avaliação motora. Porto Alegre: ArtMed.

Rosa, F. N., Almeida, G. M. F., Caon, G., Ribeiro, J., Caram, J. A., \& Piucco, E. C. (2007). Desenvolvimento motor de crianças com indicadores de dificuldades na aprendizagem escolar. R. Bras. Ci e Mov., 15(1), 45-51.

Sánchez, J. G. (2004). Dificuldades de aprendizagem e intervenção psicopedagógica. Artmed. 
Research, Society and Development, v. 10, n. 4, e2410413528, 2021

(CC BY 4.0) | ISSN 2525-3409 | DOI: http://dx.doi.org/10.33448/rsd-v10i4.13528

Saur, A. M., \& Loureiro, S. R. (2012). Qualidades psicométricas do Questionário de Capacidades e Dificuldades: Revisão da literatura. Estudos de Psicologia, 29(4), 619-629.

Seabra, A. G. (2012). Teste de Repetição de Palavras e Pseudopalavras. In A. G. Seabra, \& N. M. Dias (Orgs.), Avaliação neuropsicológica cognitiva: Linguagem oral. 2, 94-109. Memnon.

Seabra, A. G., \& Capovilla, F. C. (2012). Teste de Discriminação Fonológica. In A. G. Seabra, \& N. M. Dias (Orgs.), Avaliação neuropsicológica cognitiva: Linguagem oral. 2, 24-42. Memnon.

Seabra, A. G., Dias, N. M., \& Capovilla, F. C. (Orgs.). (2013). Avaliação neuropsicológica cognitiva: Leitura, escrita e aritmética. Memnon.

Seabra, A. G., Trevisan, B. T., \& Capovilla, F. C. (2012). Teste Infantil de Nomeação. In A. G. Seabra, \& N. M. Dias (Orgs.), Avaliação neuropsicológica cognitiva: Linguagem oral. 2, 43-86. Memnon.

Silva. C. (2013). Estratégias fonológicas como proposta de intervenção precoce para escolares com risco para dislexia. In F. H. Pinheiro, G. D. German, \& S. A. Capelli (Orgs.), Manual de estratégia para dificuldades de aprendizagem (pp. 33-47). FUNDEPE.

Soares, M. (1999). Letramento: Um tema em três gêneros. Autêntica.

Trevisan, B. T., Dias, N. M., \& Seabra, A. G. (2012). Dados normativos do Teste Infantil de Nomeação. In A. G. Seabra, \& N. M. Dias (Orgs.), Avaliação neuropsicológica cognitiva: Linguagem oral. 2, 51-53. Memnon. 